\title{
Increased risk of death from measles in children with a sibling of opposite sex in Senegal
}

\author{
Gilles Pison, Peter Aaby, Kim Knudsen
}

\author{
Abstract \\ Objective-To examine whether contracting \\ measles from a sibling of the opposite sex affects \\ mortality. \\ Design-Prospective registration during $15-20$
} years of all births and deaths, including 243 measles related deaths. Measles infection was not registered; however, as in fatal cases measles was probably contracted from a maternal sibling the risk of dying during measles outbreaks was examined in families with two boys, two girls, or a boy and a girl.

Setting-31 small villages in two rural areas of eastern Senegal.

Subjects - 766 children living in families with two children aged under 10 years during outbreaks of measles, $107(14 \%)$ of whom died of measles.

Main outcome measure-Deaths from measles, size of village, age and sex of maternal siblings.

Results - The interval between outbreaks in the same village was greater than 10 years. The risk of dying of measles was significantly related to age, increasing with the age difference between siblings and decreasing with the size of village. In a multiple logistic regression analysis adjusting for these background factors, children in families with a boy and a girl had a significantly higher mortality than children in families with two boys or two girls (odds ratio= $1 \cdot 81,95 \%$ confidence interval $1 \cdot 17$ to $2 \cdot 82$ ). The increase in risk was the same for boys and girls in families with two children one of whom was a boy and one a girl.

Conclusion-Cross sexual transmission may be an important determinant of severity of measles infection.

\section{Introduction}

In Guinea-Bissau secondary cases of measles in subjects infected from someone in their own household have a higher mortality when the infection is contracted from a subject of the opposite sex rather than of the same sex.' The same tendency was found in two different areas. Furthermore, published case reports indicate a similar tendency. As the observation points towards an important risk factor for mortality in measles infection we have attempted to find other data sets in which this phenomenon could be examined.

Twenty four Fula Bande and seven Niokholonko villages in eastern Senegal have been monitored with annual demographic surveys for 15-20 years. ${ }^{2}$ Each year the list of the people present in the compound during the preceding visit is checked, and any births, deaths, marriages, or migrations that have occurred are registered. ${ }^{-+}$During the study period many deaths from measles have been reported: 243 deaths in years with epidemics. Previous analyses from the Fula Bande area showed that measles accounts for as much as $31 \%$ of the deaths occurring between 6 months and 10 years of age, making the disease one of the most important causes of death. ${ }^{+}$Having a maternal sibling under 10 years of age was an important risk factor for dying of measles. ${ }^{+}$

It was not part of the original surveillance system to register infections, and only deaths were recorded.
Even though we do not have the information on who had measles and how it was transmitted, we have used the data on deaths from measles to test whether cross sexual transmission has an impact on deaths. If cross sexual transmission increases the proportion of cases resulting in death children whose siblings are of the opposite sex would be expected to have a higher risk of dying of measles than those with siblings of the same sex, as many children contract infection from a sibling. We therefore investigated the risk of dying of measles during an epidemic in families with only two maternal siblings: two boys, two girls, or a boy and a girl.

\section{Subjects and methods \\ BACKGROUND}

Both the Fula Bande and Niokholonko villages are located in the Département of Kedougou in eastern Senegal, near the border between Senegal and Guinea. $^{23}$ Surveillance began in 1970 among the Niokholonko, who are part of the Mandenka cultural group, and in 1975 among the Fula Bande, who are related to the Fula people of Guinea. In 1983 the Fula Bande numbered 4002 and the Niokholonko 1075.

The residential unit is a compound in which the members of an extended patrilineal family live; on average there are 13 people in a compound among the Fula Bande and somewhat more among the Niokholonko. A compound would contain one hut for each ever married woman and sometimes additional huts for unmarried adult sons or for the head of the compound, or both. Polygyny is common: there are 180 married women for 100 married men. ${ }^{23}$ When a man has several wives each has her own hut close to the others. Children sleep in their mother's hut until about the age of 15 . Teenage girls leave the compound to marry, and boys build small huts to sleep in, often with boys of their own age. Sleeping arrangements sometimes vary. Older children may sleep in the huts of old or childless women, even if their mother lives in her own hut in the compound. ${ }^{4}$

\section{DEMOGRAPHIC SURVEYS}

Once each year, usually between January and March, all villages are visited, the list of people present in each compound at the preceding visit is checked, and information is obtained on new births, marriages, migrations, deaths and (lay) causes of death. Information is usually provided by the heads of the compound or key informants in the village.

\section{MEASLES EPIDEMICS}

Measles outbreaks occur during the dry season, from October to April. Among the Fula Bande epidemics occurred in 1976-7, 1982, and 1985 and among the Niokholonko in 1973 and 1981-2. They affected only some of the villages. Seven deaths which occurred outside the time of these epidemics, usually during travels to other areas of Senegal, were not included in the analysis. As most deaths from measles occurred among children born during the study the ages of death can be considered to be fairly accurate. The study was based on the parental diagnosis of measles as the cause of death. Measles is a well known 
disease in these populations, with a specific name in the local languages. As all deaths occurred during clearly defined epidemics in the dry season, the risk of their misclassification seems limited. ${ }^{4}$ Had diagnostic errors been common, the spatial and temporal distribution of deaths from measles would have been much less distinct than indicated subsequently in our study. Measles immunisations were uncommon in this area until 1987. It is further evidence for the accuracy of parental diagnoses that no outbreaks have been subsequently reported in the four years since the 1987 immunisation campaign (see tables I and II).

\section{FAMILY COMPOSITION}

We calculated the risk of death from measles in families which just before the epidemic had two maternal siblings aged under 10 years. This analysis included only sibling pairs from villages where measles was known to be present because of deaths ascribed to measles. Children who experienced two epidemics as maternal siblings aged under 10 years of age were counted only once.

\section{STATISTICAL METHODS}

Multiple logistic regression analysis ${ }^{5}$ was used to assess the effect of opposite sex and same sex sibship, controlling for sex, age, size of village, age difference between siblings, and relative age (older or younger sibling). There was no tendency towards clustering of deaths in certain families. Clustering was therefore not considered further in the analysis.

Survival analysis techniques for censored data (Kaplan-Meier analysis) were used to calculate the median interval between epidemics within the villages. Villages in the Niokholonko area had been followed

TABLE I-Deaths from measles according to village, village size, and year of death, Fula Bande, Senegal, 1975-91

\begin{tabular}{|c|c|c|c|c|}
\hline Village & $1976-7$ & 1982 & 1985 & $\begin{array}{l}\text { Size of village (1980) } \\
\text { (No of inhabitants) }\end{array}$ \\
\hline Tiabedji & & 18 & & 416 \\
\hline Abidian & 1 & 1 & & 49 \\
\hline Lande Runde & 19 & 4 & & 328 \\
\hline Babel & 3 & & & 58 \\
\hline Tiarmalel & 3 & & & 51 \\
\hline Landieni & & 2 & & 145 \\
\hline Tioketian & 4 & & & 160 \\
\hline Bandafassi & 4 & & 6 & 212 \\
\hline Ibel & 10 & 1 & 11 & 599 \\
\hline Patassi & 1 & & & 57 \\
\hline Bandukundi & & & & 126 \\
\hline Ndebu & 7 & 1 & & 178 \\
\hline Bandi & & & & 33 \\
\hline Kessema & 15 & & & 213 \\
\hline Angoussaka & & & & 182 \\
\hline Namel & & 3 & 3 & 300 \\
\hline Kenda & & & & 51 \\
\hline Kurungoto & & & & 12 \\
\hline Lande Baitil & 5 & & & 111 \\
\hline Lande Sabere & 6 & & & 41 \\
\hline Lande Tyenar & 17 & 2 & & 195 \\
\hline Lande Boafi & 12 & 6 & & 195 \\
\hline Assoni & & & & 58 \\
\hline Nianié & & 7 & & 97 \\
\hline Total & 107 & 45 & 20 & 3867 \\
\hline
\end{tabular}

TABLE II-Deaths from measles according to village, village size, and year of death, Niokholonko, Senegal, 1970-91

\begin{tabular}{lccccc}
\hline Village & 1973 & 1976 & 1981 & 1982 & $\begin{array}{c}\text { Size of village (1979) } \\
\text { (No of inhabitants) }\end{array}$ \\
\hline Batranka & 19 & & & 18 & 215 \\
Barraboye & & & 5 & 1 & 182 \\
Banion & 10 & & 5 & & $\begin{array}{c}175 \\
51 \\
\text { Bantata } \\
\text { Lekanta }\end{array}$ \\
$\begin{array}{l}\text { Tikankali } \\
\text { Semu }\end{array}$ & & 5 & 3 & & 113 \\
Tenkoto & & 5 & 1 & 4 & 91 \\
Sekoto & & & & & \\
\hline Total & 29 & 5 & 14 & 23 & 1070 \\
\hline
\end{tabular}

TABLE III - Risk of dying of measles for children in families with only two maternal siblings aged under 10 years ${ }^{\star}$, Fula Bande and Niokholonko, Senegal, 1970-91

\begin{tabular}{|c|c|c|}
\hline & \multicolumn{2}{|c|}{$\%$ Risk (no of deaths/no alive before epidemic) } \\
\hline & $\begin{array}{c}\text { Families with same } \\
\text { sex siblings }\end{array}$ & $\begin{array}{l}\text { Families with opposite } \\
\text { sex siblings }\end{array}$ \\
\hline Total & $11(38 / 353)$ & $17(69 / 413)$ \\
\hline \multicolumn{3}{|l|}{ Sex: } \\
\hline Boys & $10(18 / 183)$ & $16(33 / 205)$ \\
\hline Girls & $12(20 / 170)$ & $17(36 / 208)$ \\
\hline \multicolumn{3}{|l|}{ Age (years): } \\
\hline $0-2$ & $18(23 / 127)$ & $23(35 / 154)$ \\
\hline $3-5$ & $8(10 / 128)$ & $16(26 / 158)$ \\
\hline $6-9$ & $5(5 / 98)$ & $8(8 / 101)$ \\
\hline \multicolumn{3}{|l|}{ Relative age: } \\
\hline Youngest & $14(26 / 184)$ & $22(45 / 209)$ \\
\hline Oldest & $7(12 / 169)$ & $12(24 / 204)$ \\
\hline \multicolumn{3}{|c|}{ Age difference years: } \\
\hline $1-3$ & $9(18 / 197)$ & $15(42 / 273)$ \\
\hline $4-9$ & $13(20 / 156)$ & $19(27 / 140)$ \\
\hline \multicolumn{3}{|c|}{ Size of village (no of inhabitants): } \\
\hline$<100$ & $14(5 / 37)$ & $41(14 / 34)$ \\
\hline $100-199$ & $11(12 / 112)$ & $20(24 / 122)$ \\
\hline$\geqslant 200$ & $10(21 / 204)$ & $12(31 / 257)$ \\
\hline \multicolumn{3}{|c|}{ Families with two children aged under 5 years } \\
\hline & $9(10 / 111)$ & $18(26 / 141)$ \\
\hline
\end{tabular}

${ }^{\star}$ Children only from villages with deaths from measles.

from 1970 to 1991 and in the Fula Bande area from 1975 to 1991 . Before the 1987 national immunisation campaign there had been no systematic immunisation in the area. The period of observation for calculating intervals between epidemics was censored in 1987.

\section{Results}

During the three epidemics among the Fula Bande and the Niokholonko, a total of 243 deaths from measles were registered. As found elsewhere in west Africa ${ }^{6}$ there were more older girls among the fatal cases: $25 \%(32 / 129)$ of the girls who died were aged 5 years or older compared with only $14 \%$ (16/114) of boys $\left(\chi^{2}=4.43, p<0.05\right)$. The median age at death was $2 \cdot 7$ years and was somewhat higher in girls than boys ( 2.9 years $v 2.5$ years; $\mathrm{p}=0.074$, Mann-Whitney $U$ test). The deaths occurred in six Niokholonko and 18 Fula Bande villages. The interval between epidemics depended on the size of the population (tables I and II). The median interval between epidemics was greater than nine years for villages with more than 100 inhabitants; in smaller villages it was more than 13 years.

In forty seven of the 243 deaths there was no maternal sibling under 10 years of age; 89 occurred in families with more than two children, leaving 107 deaths for further analysis. In families with only two maternal siblings under 10 years of age the risk of dying during outbreaks of measles was $14.0 \%$ (107/766) (table III). When sex, age, sibling age difference, relative age (older/younger), village size, and sex of sibship were included in a multiple logistic regression analysis sex and relative age did not show significant effects. Controlling for age, sibling age difference, and village size, the effect of cross sex sibship was significant (odds ratio $=1 \cdot 81,95 \%$ confidence interval 1.17 to $2 \cdot 82$ ). The risk of dying decreased with age and village size and increased with the age difference between siblings, all effects controlling for the other variables (table IV).

\section{Discussion}

Studies of secondary attack rates and serology in other community studies in Africa have suggested that parental diagnoses are very reliable. ${ }^{7.9}$ In this study diagnoses could not be verified by other means. It is unlikely, however, that infections other than measles would give an equally distinct pattern, with all deaths in a few months during the dry season, a long interval 
TABLE IV - Multiple logistic regression analysis of deaths from measles in 383 families with two maternal siblings aged under 10 years, Fula Bande and Niokholonko 1970-91

\begin{tabular}{|c|c|c|c|}
\hline Variables & Odds ratio & $95 \%$ Confidence interval & $p$ Value \\
\hline \multicolumn{4}{|c|}{ Sex of sibling } \\
\hline Opposite/same sex & 1.81 & $1 \cdot 17$ to $2 \cdot 82$ & 0.0082 \\
\hline \multicolumn{4}{|c|}{ Age (years) } \\
\hline $0-2 / 6-9$ & $4 \cdot 33$ & $2 \cdot 26$ to $8 \cdot 28$ & \\
\hline $3-5 / 6-9$ & $2 \cdot 38$ & 1.20 to 4.74 & 0.0000 \\
\hline \multicolumn{4}{|c|}{ Size of village (number of inhabitants) } \\
\hline$<100 / \geqslant 200$ & 3.53 & 1.89 to 6.61 & \\
\hline $100-199 / \geqslant 200$ & 1.56 & 0.98 to 2.50 & 0.0003 \\
\hline \multicolumn{4}{|c|}{ Age difference (years) } \\
\hline 4-9/1-3 & 1.57 & 1.00 to 2.44 & 0.0480 \\
\hline
\end{tabular}

between outbreaks, and a high risk of death in general for children aged under 10 (table III). The fact that these outbreaks stopped after the national immunisation campaign in 1987 is further evidence for the accuracy of the diagnoses. In eastern Senegal intervals between outbreaks in the same villages were extremely long, greater than 10 years in most cases Owing to the long interval children of the same mother would tend to contract measles during the same outbreak, often from a maternal sibling. As the proportion of cases resulting in death is unlikely to be much more than $14 \%$ for children aged under 10 years (table III) or $18 \%$ for children aged under 5 years $(85$ $480)^{6}$ it seems probable that most children aged under 10 contracted measles in the affected villages. We therefore assumed that all children aged under 10 years in a village contracted measles during an outbreak. As all studies have found that children infected at home (secondary cases) have higher mortality than the index child - that is, the child who introduces measles into the home ${ }^{7.9}$ - the children who died were particularly likely to have contracted measles from a maternal sibling. We therefore analysed the risk of death from measles in families with two children aged under 10 years in villages experiencing measles outbreaks. However, even if the analysis was limited to families with two children aged under 5 years there was a similar difference in risk of death for same sex and opposite sex pairs (table III).

Previous studies from west Africa have suggested that long intervals between epidemics lead to clustering of many cases and a higher proportion of cases resulting in death. 'This was also suggested by the data from Fula Bande and Niokholonko as the risk of death was higher in small villages which had longer intervals between epidemics. As the interval was more than 13 years in the small villages, siblings older than 10 years probably contributed to increased clustering of measles cases. The alternative interpretation would be that fewer children were infected in the larger villages. Given the high risk of death observed in this area, however, it seems unlikely that many should not have been infected and that the proportion of cases resulting in death should be considerably higher. Increased mortality from measles connected with a large age difference between siblings (table IV) has not been reported before. Though this could be coincidence, siblings of the same age presumably have similar behaviour patterns and are likely to contract measles at the same time, none becoming a secondary case. With a large age difference between siblings they may be more likely to become infected in different context, thus increasing the risk that the other sibling will become a secondary case.

When these significant background factors were taken into consideration the data on Fula Bande and Niokholonko indicated that the risk of dying was nearly twofold higher among those children with a sibling of the opposite sex. As the test is only indirect for secondary cases, this will underestimate the differential impact of contracting infection from a sibling of the opposite sex than from one of the same sex. Some fatal cases were not secondary cases in which infection was by a sibling aged under 10 years, either because the children themselves were infected outside the home or because they were infected by another older sibling aged more than 10 years. These fatal cases were presumably equally distributed between children with a sibling of the same sex and those with a sibling of the opposite sex. The differential impact of same sex and cross sexual transmission for secondary cases is therefore likely to be greater.

In the data from Bissau the difference between being infected by a sibling of the opposite or the same sex was strongest for girls. ${ }^{1}$ The data from Senegal, however, suggest that the relative risk between same sex and opposite sex sibling pairs is essentially the same for boys and girls (table III). Whereas the previous report from Bissau dealt only with children aged under 5, because there were virtually no deaths among older children this report suggests that the tendency is the same for older children.

The tendency for cross sexual transmission may not be limited to measles infection as we have found that male-female twins have a higher risk of postneonatal death the male-male or female-female twins. ${ }^{10}$ Furthermore, it was a risk factor for child mortality to have a nearest older sibling of the opposite sex..$^{10}$

The importance of cross sexual transmission should be examined further because it offers an alternative explanation of variation in mortality by sex. In European-American cultures it is usually assumed that somewhat higher mortality for boys is "natural" or "biological."' Where girls experience higher mortality, it is interpreted as a result of preferential treatment of boys. ${ }^{12}$ Such variations, however, could be due to differences in the transmission pattern. If one sex is more likely to be the index case owing to specific behaviour patterns the other sex would be at a dual disadvantage, being more likely to be intensively exposed as a secondary case ${ }^{7}$ and to be infected by someone of the opposite sex. There are some indications that girls in European-American culture more often are index cases. ${ }^{13}$ On the other hand, societies with a higher mortality from measles among females ${ }^{6} 1214$ is are Moslem, and the girls may have tended to be at home and the boys to be those who contracted infection outside the home.

There is no immediate explanation of why measles infection contracted from someone of the opposite sex is more severe. The most simple explanation would be that close contact increasing the dose of measles virus or the risk of complicating infections ${ }^{7}$ is more common as a result of transmission between a boy and a girl than between two children of the same sex. A similar difference in contact patterns has not been reported in studies of child behaviour.' It may be necessary, however, to look more specifically at interaction patterns during illness. The fact that girls had a higher age at death than boys may relate to the role of older girls taking care of younger siblings. Preferential treatment of one sex in families with children of both sexes could also have some role. However, as boys and girls had essentially the same risk in families with one girl and one boy (table III) it seems an unlikely mechanism.

No obvious behaviour pattern explaining the increased severity connected with cross sexual transmission has been identified.' As this tendency is similar in very different cultures ${ }^{10} 0^{16-18}$ a biological rather than a social mechanism may be indicated. Preliminary observations from a whooping cough epidemic in Guinea-Bissau with a very high rate of death suggested that cross sexual transmission was less important (unpublished observations). On the other hand, case reports of severe and fatal chickenpox infection indicate 
that cross sexual transmission increases severity (unpublished observations). Hence, the effect may be related to viral infections. We previously suggested that virus may take sex determinants from host cells, causing those produced in male and female hosts to be different.' This could facilitate infection of cells in individuals of the opposite sex. Alternatively, virus from someone of the same sex may be controlled more easily by the immune system. From this perspective it is important to test whether the association between cross sexual transmission and increased severity of disease is limited to viral infections or whether it is a more general phenomenon of infections transmitted directly between humans. Animal studies or laboratory experiments also seem warranted to examine the role of cross sexual transmission in severity of infection.

This study was supported by the Muséum National d'Histoire Naturelle, the Institut National d'Etudes Demographiques, the Centre National de la Recherche Scientifique (UA 49), the Institut National de la Santé et de la Recherche Médicale, and the Office de la Recherche Scientifique et Technique Outre-Mer. PA received support from the Danish Councils for Development Research, Medical Research, and Social Science Research. We thank the Ministère du Plan et de la Coopération and the Ministère de la Santé, Sénégal, for their agreement, interest, and help in our work; Sophie Auger, Josette Benaben, Francoise Branson, Sara Camara, Mamadou-Yero Diallo, Catherine Enel, Danièle Fouchier, Mussa Kebe, Kili Keita, André Langaney, Maria Ramirez, and Lampa Sadiaho, who participated or helped in collecting and coding the data.
1 Aabv P, Bukh J, Lisse IM, Smits AJ. Cross-sex transmission of infection and increased mortality due to measles. Rev Infect Dis 1986;8:138-43.

2 Pison G, Langaney A. The level and age pattern of mortality in Bandafass (Eastern Senegali: results from a small-scale and intensive multi-round survey. Population Studies 1985;39:387-405.

3 Pison G. Dynamique d'une population traditionelle: les Peul Bandé (Sénégal Oriental). Paris: Presse Universitaires de France, 1982.

4 Pison G, Bonneuil N. Increased risk of measles mortality for children with siblings among the Fula Bande, Senegal. Rev Infect Dis 1988;10:468-70.

5 McCullagh P, Nelder JA. Generalized linear models. New York: Chapman and Hall, 1983.

6 McGregor IA. Measles and child mortality in the Gambia. West Afr Med f 1964;13:251-7

7 Aaby P. Malnourished or overinfected. An analysis of the determinants of acute measles mortality. Dan Med Bull 1989;36:93-113.

8 Aaby P, Leeuwenburg J. Patterns of transmission and severity of measles infection. A reanalysis of data from the Machakos area, Kenya. $\mathcal{F}$ Infect Dis 1990;161:171-4.

9 Garenne M, Aaby P. Pattern of exposure and measles mortality in Senegal. IInfect Dis 1990;161:1088-94.

10 Aaby $\mathrm{P}$, Molbak K. Siblings of opposite sex as a risk factor for child mortality. BMF 1990;301:143-5.

11 Babbott FL, Gordon JE. Modern measles. Am f Med Sci 1954;228:334-61

12 Bhuiya A, Woityniak B, D'Souza S, Nahar L, Shaikh K. Measles case fatality among under-fives: a multivariate analysis of risk factors in a rural area of Bangladesh. Soc Sci Med 1987;24:439-43.

13 Aaby P, Bukh J, Lisse IM, Smits AJ. Risk factors in subacute sclerosing panencephalitis (SSPE): age-and sex-dependent host reactions or intensive exposure. Rev Infect Dis 1984;6:239-50.

14 Fargues P, Nassour O. Douze ans de mortalité urbaine au Sahel. Paris: Presses Universitaires de France, 1988

15 Monastiri $\mathrm{H}$. Quelques données statestiques relatives a la mortalité par rougeole dans la Commune de Tunis. La Tunisie Medical 1961;39:179-87.

16 Aaby P. Severity of measles and cross-sex transmission of infection in Copenhagen, 1915-1925. Int f Epidemiol 1991;20:504-7.

17 A Copenhagen, 1915 , Leeus A reanalysis of data from the Machakos area, Kenva. Ann Trop Paediatr (in press).

18 Aaby P, Lamb WH. Sex and transmission of measles in a Gambian village. f Infect 1991;22:287-92.

(Accepted 13 November 1991
(Medical Research Council,) Biostatistics Unit, Cambridge

S-M Gore, PHD, medical statistician

\section{World Health}

Organisation, Diarrhoeal

Disease Control

Programme, 1211 Geneva

27, Switzerland

O Fontaine, MD, medical

officer

N F Pierce, MD, medical

officer

Correspondence to: Dr

Fontaine.

BM7 1992;304:287-91

\title{
Impact of rice based oral rehydration solution on stool output and duration of diarrhoea: meta-analysis of 13 clinical trials //
}

\author{
Sheila MGore, Olivier Fontaine, Nathaniel F Pierce
}

\section{Abstract}

Objective-To define the benefit of rice oral rehydration salts solution in relation to the glucose based World Health Organisation oral rehydration salts solution for treating and preventing dehydration in patients with severe dehydrating diarrhoea.

Design-Meta-analysis using data from 13 available randomised trials that compared these two formulations.

Subjects-The studies compared 1367 patients with cholera, severe cholera-like diarrhoea, or acute non-cholera diarrhoea. 668 received the standard WHO solution and 699 the rice based solution.

Intervention-Each trial report was reviewed to determine patient eligibility, the number of patients who were randomised and the number of these excluded from analysis, details of the randomisation procedure, and the precise timing of the outcome measurements.

Main outcome measures-Stool output during the first 24 hours; weighted estimates of the difference in mean stool output between treatments.

Results - The rice solution significantly reduced the rate of stool output during the first 24 hours by $36 \%(95 \%$ confidence interval 28 to $44 \%)$ in adults with cholera and by $32 \%$ (19 to $45 \%$ ) in children with cholera. The rate of stool loss in infants and children with acute non-cholera diarrhoea was reduced by only $18 \%$ ( 6 to $30 \%)$.

Conclusions - The benefit of rice oral rehydration salts solution for patients with cholera is sufficiently great to warrant its use in such patients. The benefit is considerably smaller for children with acute, non- cholera diarrhoea and should be more precisely defined before its practical value can be judged.

\section{Introduction}

Oral rehydration therapy with the glucose and electrolyte solution recommended by the World Health Organisation and Unicef is the preferred method for treating children with dehydration due to diarrhoea, provided that they are able to drink and do not have signs of shock.' Although the solution is both safe and effective (D Mahalanabis, unpublished WHO document), it has important limitations: it neither reduces the rate of stool loss nor shortens the duration of illness. ${ }^{2.5}$ Mothers often do not understand the relation between diarrhoea and dehydration, and their primary concern, shared by many health workers, is to see the diarrhoea stop. This probably accounts for the continuing widespread use of ineffective "antidiarrhoeal" drugs and antibiotics to treat diarrhoea instead of, or in addition to, oral rehydration salts solution (WHO diarrhoeal diseases control programme, seventh programme report, 1988-89, 1990).

If a packaged oral rehydration salts formulation could be developed that not only had the positive features of the WHO formulation, including low cost and safety and stability during prolonged storage, bu also substantially reduced the duration of diarrhoea or the rate of stool loss, it would have considerable advantages. In particular, it could be promoted as having a real antidiarrhoeal effect. This should improve its acceptance and use by both health workers and mothers, especially if its benefits were sufficiently great 